\title{
Estudo de caso: avaliação ergonômica como conforto ambiental integrado em São Paulo'
}

\section{Case study: ergonomic evaluation as integrated environmental comfort in São Paulo}

\author{
Luiz, Larissa A.'; Novaes, Gabriel B. A.2; Monteiro, Leonardo M.3; Mülfarth, \\ Roberta C. K. 4 \\ 1 Universidade de São Paulo, São Paulo, Brasil, larissa.azevedo.luiz@usp.br \\ 2 Universidade de São Paulo, São Paulo, Brasil, gabriel.novaes@usp.br \\ 3 Universidade de São Paulo, São Paulo, Brasil, leo4mm@usp.br \\ 4 Universidade de São Paulo, São Paulo, Brasil, rkronka@usp.br
}

\begin{abstract}
RESUMO
O trabalho propõe uma reflexão sobre a forma integrada com que percebemos as diferentes variáveis ambientais no espaço urbano, trazendo uma compreensão do conceito de "ergonomia" enquanto conforto ambiental integrado. É, portanto, uma análise crítica do aspecto interdisciplinar da ergonomia, feita com base em levantamentos empíricos realizados em diferentes épocas e locais de São Paulo contemplando medições in loco de dados ambientais e questionários aplicados aos pedestres. Além de entender a ergonomia como uma área multidisciplinar muito mais complexa do que os aspectos dimensionais, as pesquisas auxiliaram na compreensão do desempenho global dos espaços externos e no entendimento de que o conforto do usuário vai além de valores de temperatura e níveis de ruídos, observando que a percepção do espaço da via é um fator subjetivo decisivo para a escolha do usuário por um espaço em detrimento de outro. Conclui-se que a ergonomia aplicada à leitura do espaço urbano aberto deve ser compreendida como uma percepção completa do ambiente e que o conforto se caracteriza por uma complexa relação de fatores ambientais, sociais, psicológicos e culturais que devem ser lidos em comunhão. Não basta definir números mínimos e máximos de quantidade de luz, calor e ruído para qualificar um espaço.
\end{abstract}

Palavras-chave: conforto ambiental, conforto urbano, ergonomia.

\section{ABSTRACT}

The paper proposes a reflection on the integrated way with which we perceive the different environmental variables in the urban space, bringing an understanding of the concept of "ergonomics" as integrated environmental comfort. It is, therefore, a critical analysis of the interdisciplinary aspect of ergonomics, based on empirical surveys conducted at different times and locations in São Paulo, contemplating on-site measurements of environmental data and questionnaires applied to pedestrians. In addition to understanding ergonomics as a much

\footnotetext{
${ }^{1}$ LUIZ, Larissa A.; NOVAES, Gabriel B. A.; MÜLFARTH, Roberta C. K.; MONTEIRO, Leonardo M. Ergonomia como conforto ambiental no espaço urbano. In: ॥ SIMPÓSIO NACIONAL DE GESTÃO E ENGENHARIA URBANA: SINGEURB, 2019, São Paulo. Anais... Porto Alegre: ANTAC, 2019.
} 
more complex multidisciplinary area than dimensional aspects, the research has helped to understand the overall performance of outdoor spaces and to comprehend that user comfort goes beyond temperature values and noise levels, noting that the perception of street space is a decisive subjective factor for the user's choice for one space over another. It is concluded that the ergonomics applied to the reading of the open urban space should be understood as a complete perception of the environment and that comfort is characterized by a complex relation of environmental, social, psychological and cultural factors that should be read in communion. It is not enough to set minimum and maximum values of light, heat and noise to qualify a space.

Keywords: environmental comfort, urban comfort, ergonomics.

\section{INTRODUÇÃO}

A inserção do conforto ambiental, em particular da ergonomia, na concepção dos projetos urbanísticos remete à própria definição de conforto, que, frequentemente, dada sua amplitude e gama de variáveis incidentes, é feita de forma generalista. É comum que as diversas especialidades associadas à percepção ambiental do espaço sejam tratadas de forma isolada, ainda que a percepção humana sempre incorra na assimilação integrada de todas as variáveis simultaneamente.

Na construção do meio urbano, por vezes, não se leva em conta os principais aspectos e necessidades do usuário local, e, em grande parte da cidade, vemos pedestres submetidos a condições ambientais adversas, como ruído e insolação excessivos, corredores de vento, falta de iluminação noturna, ofuscamento, altas temperaturas, calçadas esburacadas, etc. Neste sentido, compreender as diferentes condições ambientais que se somam e compõem o espaço urbano é essencial para um desenho de cidade que proporcione melhor qualidade de vida.

\section{ERGONOMIA COMO CONFORTO AMBIENTAL INTEGRADO NO ESPAÇO URBANO ABERTO}

Cada pedestre possui uma percepção diferente do espaço urbano, englobando não só as variáveis e interferências do espaço físico, mas também fatores subjetivos, psicológicos, ambientais e físicos (SCHMID, 2005). A abordagem do conforto no projeto é, normalmente, fixada nos aspectos físicos do espaço e os demais são negligenciados. No caso da abordagem da ergonomia, as discussões se restringem à antropometria e acessibilidade.

É fundamental compreender que a contribuição da ergonomia no desenho urbano pode ser a definição de condições de mobilidade, proporções e dimensões em ambientes construídos, desde que se considere o conforto integrado. Isto pressupõe considerar a percepção individual do espaço, influenciada por variáveis que englobam todos os campos do conforto, mesmo aquelas que não estejam diretamente relacionadas com o dimensionamento.

Uma série de fatores ambientais influencia na porcentagem de pedestres em conforto nas vias, e vários são os desafios encontrados para propor melhorias, visto que a maior dificuldade parte da própria compreensão do conforto e desconforto dos pedestres frente às características das vias. A partir disso, a ergonomia deve ser compreendida como uma percepção complexa do pedestre no ambiente a partir da incidência de fatores ambientais diversos, como pode ser visto na Figura 1. 


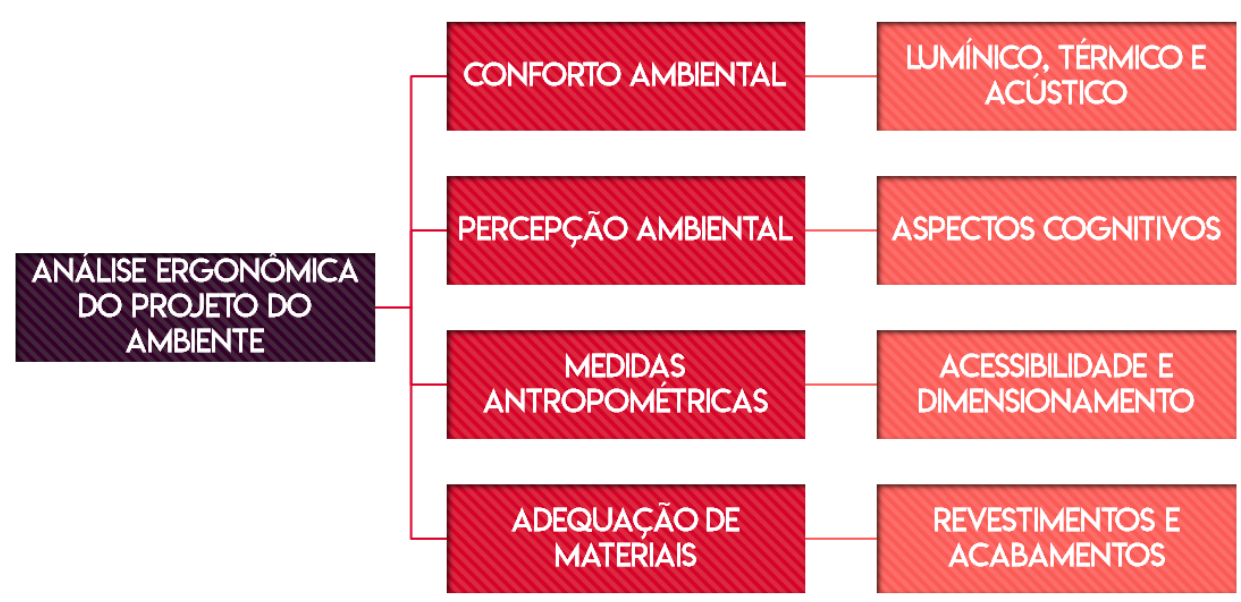

Fonte: Villarouco (2005)

\section{ESTUDO DE CASO: AVALIAÇÃO ERGONÔMICA COMO CONFORTO AMBIENTAL INTEGRADO EM SÃO PAULO}

\subsection{Objetivo}

Para os projetos "Avaliação, sob o enfoque ergonômico, de edifícios modernistas construídos em São Paulo entre 1930 e 1964: áreas externas" (LUIZ, 2016) e "Conforto Termoacústico do Pedestre em São Paulo e Influência de Outras Variáveis Ambientais" (NOVAES, 2015), foi realizado um estudo de caso, ao longo de 2015, nas regiões da Avenida Paulista e da República, com o objetivo de avaliar os fatores ambientais quantitativos, qualitativos e subjetivos - e suas inter-relações - que influenciam na percepção do pedestre em relação ao conforto no ambiente construído, compreendendo a ergonomia como conforto ambiental integrado.

\subsection{Metodologia}

Através de medições empíricas de dados ambientais, foram obtidas informações quantitativas (térmicas microclimáticas, acústicas, fluxos de pedestres e veículos) que caracterizam a ambiência de cada espaço.

As condições acústicas foram caracterizadas através de medição e cálculo dos níveis de ruído equivalentes, utilizando o método BISTAFA (2006). A ambiência térmica foi caracterizada pela "Temperatura Equivalente Percebida (TEP)", índice de conforto térmico, proposto por MONTEIRO (2008), que combina valores de temperatura do ar, velocidade do vento, umidade relativa e temperatura de globo medidos no local.

A análise dos aspectos qualitativos dos espaços abrangeu o mapeamento de problemas antropométricos, condições físicas e de manutenção de calçadas e morfologia urbana. A avaliação subjetiva foi feita através de questionários aplicados aos pedestres sobre o conforto e percepção das condições do espaço em relação à sensação de frio e calor, à insolação, à luz, ao ruído, ao mobiliário, às instalações, ao tráfego, à segurança, à vegetação, etc.

O processo de trabalho combina, portanto, após embasamento bibliográfico, uma caracterização quantitativa, qualitativa e subjetiva dos espaços analisados para a obtenção dos resultados. 


\subsection{Locais de Avaliação}

A amostra consistiu em aproximadamente 500 entrevistas em 6 pontos durante 3 dias em março, abril e julho de 2015 (LUIZ, 2016 e NOVAES, 2015). Os pontos de medição contemplaram, na República, três pontos na Avenida Ipiranga avaliados em abril/2015 nas calçadas do Edifício Copan, do Edifício Itália e do Edifício Esther. E contemplaram, na Avenida Paulista, três pontos em março e julho de 2015 nas calçadas do Conjunto Nacional, do Edifício Sul-Americano (Itaú) e no pátio interno do Conjunto Nacional.

\subsection{Resultados}

Observou-se que há uma correlação direta entre a largura do passeio e o conforto do pedestre. Passeios bem dimensionados devem possuir largura livre suficiente para acomodar o tráfego de pessoas, mas sem excessos: calçadas estreitas não só atrapalham o caminhar das pessoas, como evidenciam obstáculos, enquanto calçadas excessivamente largas podem gerar dificuldades de manutenção e iluminação e a percepção de espaço inabitado e inseguro.

Mesmo quando a largura é adequada, a percepção da calçada é influenciada pela qualidade e adequação do pavimento (acabamento, manutenção, etc.), presença de obstáculos (árvores, postes, telefones, bancas, pontos de ônibus, etc.), presença de desníveis e irregularidades, manutenção, limpeza e estética do piso.

É comum, em São Paulo, passeios de pedestres com remendos e irregularidades associadas às diferentes características de piso e condições de assentamento, falhas associadas à falta de manutenção e aos diversos reparos sofridos a cada novo serviço, buracos, bueiros com tampas ausentes ou danificadas, etc. Há ainda a variedade de pisos, uma vez que o proprietário do lote é o responsável pela calçada em frente ao seu imóvel.

Para a calçada, foram observadas ainda outras situações problemáticas que não podem ser quantificadas, como o medo de atropelamento que aumenta conforme é reduzida a largura do passeio, conforme cresce a quantidade de pedestres na calçada ou conforme aumenta a velocidade dos veículos na via, e o medo de assaltos, o qual tem uma tendência de crescimento em duas situações: quando a rua está esvaziada de pedestres ou quando está muito cheia.

Além das condições do passeio, evidenciou-se que, em São Paulo, o conforto térmico se apresenta como fator mais incidente no conforto do pedestre. O desconforto térmico interfere na tolerância dos pedestres às demais variáveis ambientais, enquanto que a exposição à radiação solar é extremamente incisiva sobre o conforto geral do usuário.

O conforto acústico também figura como um dos elementos mais incidentes sobre a satisfação do usuário com a via, entretanto, o nível equivalente de ruído não é o único fator relevante. As fontes de ruído e as expectativas do pedestre em função do porte e do uso da via podem alterar drasticamente a tolerância do usuário ao ruído.

A iluminação natural também pode gerar desconforto, pois os cânions urbanos, a exemplo das áreas da República e da Avenida Paulista, podem gerar espaços abertos com pouco acesso de visibilidade ao céu, eventualmente com condições prejudicadas de insolação e iluminação natural, e o ofuscamento causado por reflexos solares em edifícios envidraçados e veículos foi apontado por uma quantidade significativa de pedestres como um fator de desconforto, em especial na Avenida Paulista.

Foi possível ainda observar o aumento no fluxo de pedestres no horário de almoço, uma vez que, tratando-se de regiões com grande ocupação comercial há um enorme número de pessoas se deslocando a pé para frequentar restaurantes e lanchonetes no entorno. Essa dinâmica aumenta a necessidade de mobiliário nesse horário, pois as calçadas se tornam um espaço de permanência, convivência e descanso.

Ressalta-se que o mobiliário deve ser implantado adequadamente. Os bancos devem ter encosto e estarem fora da faixa livre, assim como postes, bancas, árvores e bicicletários. Em 
São Paulo podemos notar que as redes de infraestrutura foram implantadas de forma independente e não dialógicas, resultando numa série de interferências nos pavimentos das calçadas, já que existem diversas obras de manutenção para os serviços instalados sob e sobre as calçadas (água, energia, internet, etc.).

Ao ser questionado de forma geral sobre o conforto no início do questionário, o usuário está tão adaptado à qualidade ruim dos passeios, que ele se declara em conforto sem analisar todos os aspectos do ambiente, mas, posteriormente, ao ser questionado sobre aspectos específicos, ele encontra uma série de queixas.

É importante observar que a percepção do espaço da via é um fator subjetivo que pode ser decisivo para a escolha do usuário por um espaço em detrimento de outro. Além de entender a ergonomia como uma área multidisciplinar muito mais complexa do que os aspectos dimensionais, as pesquisas auxiliaram na compreensão do desempenho global dos espaços externos, no entendimento de que o conforto do usuário vai além de valores de temperatura e níveis de ruídos.

Analisando os espaços públicos das vias em frente aos edifícios escolhidos, foi possível observar que nem sempre o resultado lógico esperado em função apenas dos dados quantitativos é o encontrado. Por exemplo, o fato de a quantidade de pessoas em desconforto acústico na Avenida Paulista ser menor do que na República apesar de ter apresentado maiores níveis de ruído equivalente.

O conforto do usuário se caracteriza por uma complexa relação de fatores ambientais, sociais, psicológicos e culturais que devem ser lidos em comunhão para uma proposta efetiva de projeto visando o conforto. Não basta definir números mínimos e máximos de quantidade de luz, calor e ruído para qualificar um espaço.

\section{CONCLUSÕES}

A ergonomia aplicada à leitura do espaço urbano aberto deve ser compreendida como uma percepção completa e complexa do pedestre em relação ao ambiente onde se encontra a partir da incidência de uma série de fatores ambientais de diversas características.

As ruas não devem ter apenas calçadas com largura mínima de 1,20m e leito carroçável asfaltado. Ficou evidente nesta pesquisa que a largura, apesar de ser muito importante, pode ser um fator secundário para o conforto do usuário. Uma série de fatores ambientais levam a uma maior porcentagem de pedestres em situação de conforto, e são os desafios encontrados pelos intervenientes para propor melhorias nas calçadas de vias existentes, uma vez que o verdadeiro desafio parte da própria compreensão das melhores situações de conforto e desconforto dos pedestres frente às variações das características das vias.

Uma rua em São Paulo, para ser considerada confortável pela maioria dos pedestres, deve proporcionar proteção contra a exposição excessiva ao sol, tanto áreas abertas ao céu quanto espaços sombreados. Deve permitir a circulação do ar em condições que favoreçam a remoção adequada da polvição e do calor. Em paralelo, a calçada deve se adequar à largura total da rua, ao tamanho dos edifícios e ao fluxo de pedestres, apresentando uma faixa de circulação livre de obstáculos ou problemas de piso, com atenção à adequação da textura do piso e à presença de mobiliário adequado.

\section{AGRADECIMENTOS}

Agradecemos ao LABAUT/FAUUSP, à FAPESP e ao CNPq.

\section{REFERÊNCIAS}

BISTAFA, S. R. Acústica Aplicada ao Controle de Ruído. São Paulo: Editora Edgard Blücher Ltda., 2006. 
LUIZ, L. A. Avaliação, sob o enfoque ergonômico, de edifícios modernistas construídos em São Paulo entre 1930 e 1964 - Áreas Externas. São Paulo: Relatório Final de Iniciação Científica. Faculdade de Arquitetura e Urbanismo da Universidade de São Paulo (FAU USP), 2016.

MONTEIRO, L. M. Modelos Preditivos de Conforto Térmico - Quantificação de relações entre variáveis microclimáticas e de sensação térmica para avaliação e projeto de espaços abertos. São Paulo: Tese de Doutorado. Faculdade de Arquitetura e Urbanismo da Universidade de São Paulo (FAU USP), 2008.

NOVAES, G. A. Conforto Termoacústico do Pedestre em São Paulo e Influência de Outras Variáveis Ambientais. São Paulo: Relatório Final de Iniciação Científica. Faculdade de Arquitetura e Urbanismo da Universidade de São Paulo (FAU USP), 2015.

SCHMID, A. L. A Ideia de Conforto - Reflexões sobre o Ambiente Construído. Curitiba: Pacto Ambiental, 2005.

VILLAROUCO, V. Identificação de parâmetros para concepção de espaços ergonomicamente adequados à habitação social. Anais do $5^{\circ}$ Ergodesign - $5^{\circ}$ Concresso Internacional de Ergonomia e Usabilidade de Interfaces Humano-Tecnologia - Produtos, Programa, Informação e Ambiente Construído. Rio de Janeiro: Laboratório de Ergodesign e Usabilidade de Interfaces (LEUI) da Pontifícia Universidade Católica do Rio de Janeiro (PUCRio). 2005. 